\title{
圧電セラミックスのドメイン特性に関する研究
}

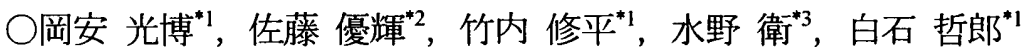

\section{A Study of the Domain Properties in Piezoelectric Ceramics}

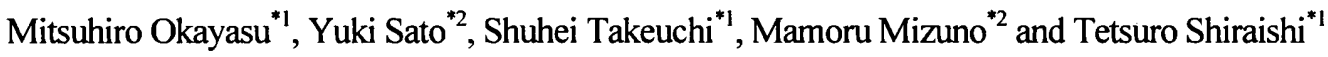 \\ ${ }^{1}$ Department of Materials Science and Engineering, Ehime University \\ 3 Bunkyo-cho, Matsuyama, Ehime, 079-8577, Japan \\ ${ }^{23}$ Department of Machine Intelligence and Systems Engineering, Akita Prefectural University \\ 84-4 Aza Ebinokuchi, Tuchiya, Yurihonjo, Akita, 015-0055, Japan
}

The domain walls and domain characteristics have been examined experimentally. In this study, a conventional lead zirconate titanate (PZT) piezoceramics were used. The specimen was designed to be a rectangular block shape. The specimens were loaded mechanically and electrically. The domain and domain-wall directions were altered with different direction. The domain direction was switched 90 degree by the mechanical loading, i.e., domain switching, where the (002) peak decreased and the (200) peak increased. In contrast, the domain wall direction was altered 90 degree when loaded electrically. With the applied stresses, domain direction and domain wall direction can be controlled. From the domain properties, it is considered that piezoelectric properties of PZT ceramics can be controlled by the applied stress.

Keywords: piezoelectric ceramic; domain switching; Domain orientation; Domain wall

\section{Introduction}

PZT piezoelectric ceramics have been used widely in the world due to the high piezoelectric properties and high mechanical properties. The PZT piezoelectric ceramics have been employed for various actuators, buzzers and sensors. Because the sensor and actuator are required to have reliable and durable, the ceramics should be made with high quality. In this instance, the piezoelectric properties are attributed to self-induced or external stress. It is considered that there is relationship between the applied stress with mechanically and electrically and the material properties of PZT ceramics. In addition, the piezoelectrical properties are affected by the domain characteristics, e.g., domain and domain-wall direction. Thus, the domain characteristic is significant factors to determine the piezoelectric properties. However relationship between the domain characteristics and the applied stress of PZT ceramics has not been clarified. The domain structures of the PZT ceramics were investigated after the electrical and mechanical loads were applied.

\section{Experimental}

\subsection{Material and experimental procedures}

In this work, a commercial PZT ceramic of nominal composition $\mathrm{PbZrTiO}_{3}$ was selected. The PZT ceramics were formed with tiny grain of $5 \mu \mathrm{m}$ in diameter and the density of $7.7 \mathrm{~g} / \mathrm{cm}^{3}$, examined by Archimedes method.

*1 正員，愛媛大学（干790-8577 爱媛県松山市文京町 3)

*2学生員, 秋田県立大学

*3正員, 秋田県立大学

E-mail: okayasu.mitsuhiro.mj@ehime-u.ac.jp

Silver-based electroplated layers were coated to two sides of the specimen faces by a firing process in ambient atmosphere. The PZT ceramics adopt a perovskite tetragonal structure with aspect ratio $\mathrm{c} / \mathrm{a}=1.014$. In this study, un-poled samples were used to investigate the domain orientation after the applied mechanical and electrical loadings. Depolarization was conducted using a muffle furnace at $633 \mathrm{~K}$ for $30 \mathrm{~min}$ in air.

Fig. 1 shows a schematic illustration of the specimens. Two rectangular block specimens were used for (a) the mechanical loading test (long rectangular bar) and (b) the electrical loading test (short rectangular one). The domain characteristics were examined after the mechanical stress is applied to the long rectangular specimen in various regions, i.e., tensile stress and compressive stress, as indicated in Fig. la.

(a)

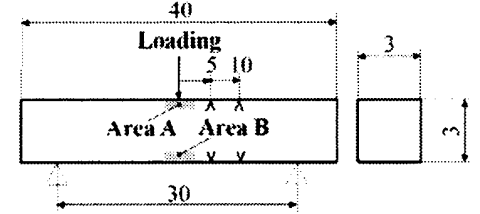

(b)
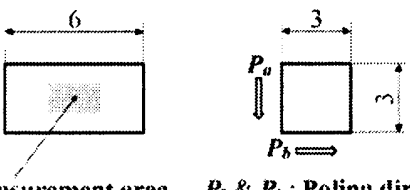

Measurement area $P_{b} \& P_{b}$ : Poling direction

Fig. 1 Schematic illustrations of the test specimens

日本機械学会[No.12-5]M \&M2012 材料カ学カンファレンス CD-ROM 論文集[2012.9.22-24.松山] 
The domain orientations were investigated by XRD analysis. In the XRD analysis, an X'Pert Pro system with a $\mathrm{Cu}$ tube source was utilized at $8 \mathrm{keV}$. The bending stress was applied by stroke control at $1 \mathrm{~mm} / \mathrm{min}$ using a screw driven type universal testing machine with $10 \mathrm{kN}$ capacity. On the other hand, the domain wall characteristics were investigated after applied electrical stress using the short rectangular specimen, as shown in Fig. 1b. The electrical stress, applied by electric field of DC $5 \mathrm{kV} / \mathrm{mm}$ for $10 \mathrm{~min}$ in silicon oil, was carried out using Model 610E, Trek Inc.

\section{Experimental results}

\subsection{Domain switching characteristics}

Fig. 2 shows the X-ray diffraction pattern of the PZT ceramics (bending specimen) [1]. In this sample, the domain orientation of $\left(\begin{array}{lll}2 & 0 & 0\end{array}\right)$ and $\left(\begin{array}{lll}0 & 0 & 2\end{array}\right)$ peaks was obtained by the diffraction intensity at the 2 theta of 43.638 degree and 44.888 degree, respectively. With the change of the ratio of $\left(\begin{array}{lll}2 & 0 & 0\end{array}\right)$ and $\left(\begin{array}{lll}0 & 0 & 2\end{array}\right)$ peaks, the domain direction was identified. The X-ray diffraction analyses, showing the $\left(\begin{array}{lll}2 & 0 & 0\end{array}\right)$ and $\left(\begin{array}{lll}0 & 0 & 2\end{array}\right)$ peaks for the de-poled PZT ceramics were indicated by the dashed lines, where Area $A$ and $B$ are related to the tensile and compressive stress regions. From Fig. 2, it is clear that different domain formation is observed, in which $90^{\circ}$ domain switching occurs with different severity depending on the measurement area. As the compressive stress is applied in Area A, the $\left(\begin{array}{lll}2 & 0 & 0\end{array}\right)$ peak decreases and the $\left(\begin{array}{lll}0 & 0 & 2\end{array}\right)$ peak increases. In contrast, the $(2$ $00)$ peak increases and the $\left(\begin{array}{lll}0 & 0 & 2\end{array}\right)$ peak decreases in Area B.
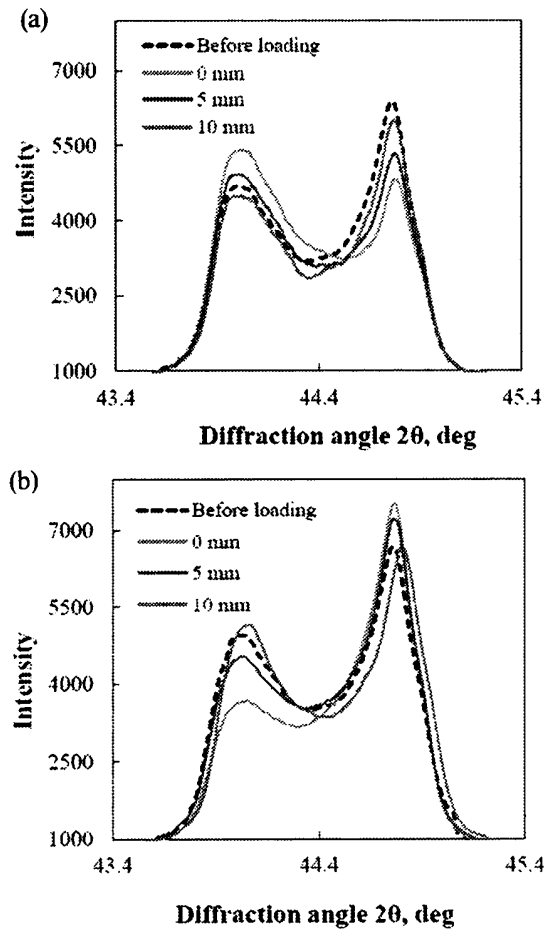

Fig. $2 \mathrm{X}$-ray diffraction profiles of the bending specimens measured in different positions on (a) Area A and (b) Area B.
The strong $90^{\circ}$ domain switching occurs near the loading position, but the extent of domain switching is decrease in the area far away from the loading point. No clear domain switching is detected in the both Area A and B more than $10 \mathrm{~mm}$. This reason would be simply considered to be affected by the low applied stress. In this result, it is clear that the domain switching direction is altered, depending on the stress direction, which is schematically illustrated in Fig. $3[1]$.

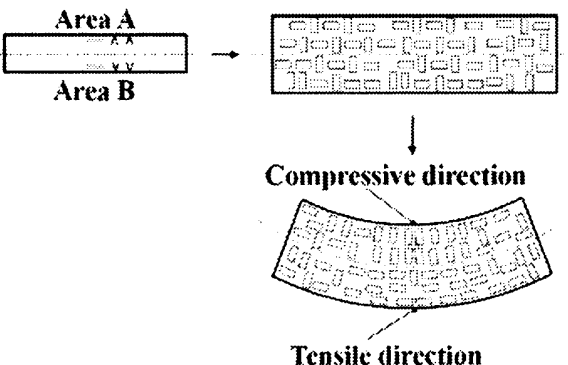

Fig. 3 Schematic illustration of $90^{\circ}$ switching characteristics in the bending specimen

\subsection{Domain wall characteristics}

Fig. 4 displays the SEM images for the PZT ceramics after the poling processes shown in Fig. $1 \mathrm{~b}$, where the direction of the poling process is indicated by the arrows. From Fig. $4 a$ and $b$, the domain walls with fine pitch are clearly observed on the grain surfaces although the direction of domain wall is different. It seems that the domain walls seem to be aligned perpendicular to the poling direction. To understand the domain wall characteristics more clearly, the angle of the domain wall direction on the basis of the poling direction was investigated. With the examination of 50 grains,

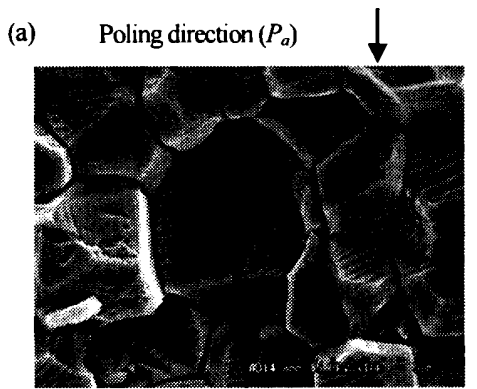

(b)

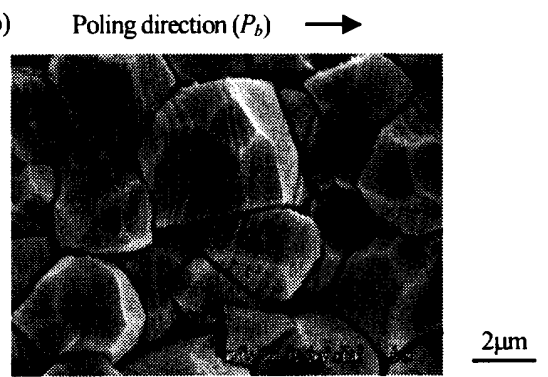

Fig. 4 SEM images of sample surfaces showing the domain walls 
it appeared that more than $80 \%$ domain walls are oriented in-between 70 and 110 degree [2]. However, the reason for this is not clarified now, which will be discussed in the future.

\section{Conclusions}

1) Different trends of domain switching pattern are obtained, depending on the mechanically applied stress. As the compressive stress is increased, the (200) peak decreases and the $\left(\begin{array}{lll}0 & 0 & 2\end{array}\right)$ peak increases. An opposite trend of domain switching pattern is detected in the tensile stress area.

2) The domain switching occurs most significantly near the loading point although the severity of the domain switching decreases in the measurement area far away from the loading position. Domain switching can't be detected in the area more than $10 \mathrm{~mm}$ away from the loading point.

3) The domain and domain wall direction can be aligned by the mechanical and electrical applied load, respectively. The domain walls are aligned perpendicular to the poling direction.

\section{References}

1. M. Okayasu et al., A study of the effects of vibration on the electric power generation properties of lead zirconate titanate piezoelectric ceramic, Ceramics International, 38(6): 2012;4445-4451.

2. M. Okayasu et al., Effect of domain wall characteristics on material properties of lead zirconate titanate piezoelectric ceramics, Advances in Applied Ceramics, 111(4):2012;187 -195 . 